\title{
A B B REVIATIONS
}

$\begin{array}{ll}< & \text { is derived from (in etymologies) } \\ \text { app. } & \text { appendix } \\ \text { dat. } & \text { dative case } \\ \text { dim. } & \text { diminutive } \\ \text { Eng. } & \text { English } \\ \text { Fr. } & \text { French } \\ \text { gen. } & \text { genitive case } \\ \text { Gk. } & \text { Greek } \\ \text { Gk. App. } & \text { Greek Appendix (to Tannen and Öztek 1977) } \\ \text { Heb. } & \text { Hebrew } \\ \text { mod. } & \text { modern } \\ \text { NP } & \text { noun phrase } \\ \text { pers. comm. } & \text { personal communication } \\ \text { RP } & \text { Röyte Pomerantsen (Olsvanger 1947/1965) } \\ \text { Russ. } & \text { Russian } \\ \text { Tk. } & \text { Turkish } \\ \text { Tk. App. } & \text { Turkish Appendix (to Tannen and Öztek 1977) } \\ \text { VP } & \text { verb phrase } \\ \text { Yid. } & \text { Yiddish } \\ \text { YP } & \text { Yiddish Proverbs (Ayalti 1949) } \\ & \end{array}$


